\title{
Abnormal Long-Lasting Synaptic Plasticity and Cognition in Mice Lacking the Mental Retardation Gene Pak3
}

\author{
Jinsong Meng, ${ }^{1,2,3}$ Yanghong Meng, ${ }^{1,2,3}$ Amanda Hanna, ${ }^{4}$ Christopher Janus, ${ }^{1,4}$ and Zhengping Jia ${ }^{1,2,3}$ \\ ${ }^{1}$ Brain and Behavior Program and ${ }^{2}$ Division of Neurology, The Hospital for Sick Children, Toronto, Ontario, Canada M5G 1X8, ${ }^{3}$ Department of Physiology, \\ University of Toronto, and ${ }^{4} \mathrm{Center}$ for Research in Neurodegenerative Diseases, Toronto, Ontario, Canada M5S 3H2
}

\begin{abstract}
Mutations in the Pak3 gene lead to nonsyndromic mental retardation characterized by selective deficits in cognition. However, the underlying mechanisms are yet to be elucidated. We report here that the knock-out mice deficient in the expression of p21-activated kinase 3 (PAK3) exhibit significant abnormalities in synaptic plasticity, specifically hippocampal late-phase long-term potentiation, and deficiencies in learning and memory. A dramatic reduction in the active form of transcription factor cAMP-responsive element-binding protein in the knock-out mice implicates a novel signaling mechanism by which PAK3 and Rho signaling regulate synaptic function and cognition.
\end{abstract}

Key words: mental retardation gene; Rho signaling; hippocampal LTP; CREB; learning and memory; actin

\section{Introduction}

Mental retardation (MR), defined by global deficiencies in cognitive abilities, is the leading cause of serious handicap in children and young adults (Chiurazzi and Oostra, 2000; Chelly and Mandel, 2001). In syndromic form of MR, cognitive impairments are usually associated with other physical and neurological deficits. A considerable progress has been made in understanding syndromic MR, including the establishment of several animal models (Dutch-Belgium Fragile X Consortium, 1994; Silva et al., 1997; Costa et al., 2001; Bourtchuladze et al., 2003; Alarcon et al., 2004; Korzus et al., 2004). In contrast, nonsyndromic MR is characterized by reduced cognitive function without any other clinical features, thus providing the most direct approach to specifically study the neurobiology of cognition and pathogenesis of MR (Chelly and Mandel, 2001; Ramakers, 2002). However, much less is known about the mechanisms of the latter form of MR.

To date, $>11$ genes have been identified to be involved in $\mathrm{X}$ chromosome-linked nonsyndromic mental retardation (MRX) (Chelly and Mandel, 2001; Van Galen and Ramakers, 2004). At least three of them, including the Pak3 gene, encode components involved in the signal transduction pathways regulated by the Rho family GTPases, small GTP-binding proteins known to be important in multiple cellular processes, particularly in the reg-

Received Jan. 4, 2005; revised June 2, 2005; accepted June 4, 2005.

This work was supported by grants from the Canadian Institutes of Health Research (CIHR), by the Heart and Stroke Foundation of Canada, by the Premier's Research Excellence Award, and by The Hospital for Sick Children Foundation. C.J. was supported by grants from the Alzheimer Society of Canada, the Institute of Aging (ClHR), and the Alzheimer Society of Saskatchewan. Y.M. has been supported by fellowships from The Hospital for Sick Children training center and CIHR, and Z.J. is a CIHR New Investigator. We are grateful to J. Hwang, Y. M. Heng, Yu Zhang, G. Lu, Z. Zhou, Z. Todorovski, and Suhail Asrar for technical assistance.

Correspondence should be addressed to Zhengping Jia, Brain and Behavior Program, The Hospital for Sick Children, 555 University Avenue, Toronto, Ontario, Canada M5G 1X8. E-mail: zhengping.jia@sickkids.ca.

A. Hanna's and C. Janus's present address: Department of Neuroscience, Mayo Clinic Jacksonville, 4500 San Pablo Road, Jacksonville, FL 32224.

DOI: 10.1523/JNEUROSCI.0028-05.2005

Copyright $\odot 2005$ Society for Neuroscience $\quad$ 0270-6474/05/256641-10\$15.00/0 ulation of actin dynamics (Van Alest and D'Souza-Schorey, 1997; Allen et al., 1998; Hall, 1998). Because the actin cytoskeleton is important for cell morphology and motility, it is thought that Rho proteins affect cognition through regulating neuronal structures, including the dendritic spine, an actin-rich postsynaptic specialization in which the majority of excitatory synapses are formed (Matus, 2000; Sorra and Harris, 2000; Bonhoeffer and Yuste, 2002; Ramakers, 2002; Lamprecht and LeDoux, 2004). Accordingly, spine deficits are associated with many types of mental disorders, including MR (Sorra and Harris, 2000; Ramakers, 2002). However, in vivo studies of the MRX genes are currently limited.

In this study, we generated and analyzed knock-out mice deficient in the expression of the MRX gene Pak3. The Pak3 gene encodes a serine/threonine protein kinase that belongs to a family of p21-activated kinases (PAK1-3), the activity of which is directly stimulated by the Rho GTPase (Van Alest and D'SouzaSchorey, 1997; Allen et al., 1998; Hall, 1998; Bokoch, 2003; Zhao and Manser, 2005). To our surprise, we found that PAK3 knockout mice showed no deficits in either neuronal structures or the actin cytoskeleton. However, these mice were selectively impaired in late-phase hippocampal long-term potentiation (LLTP), a distinct form of long-lasting synaptic plasticity involving new gene expression (Bliss and Collingridge, 1993; Malenka and Nicoll, 1999; Kandel, 2001; Silva, 2003; Kelleher et al., 2004). The knock-out mice showed a dramatic reduction in the active form of cAMP-responsive element-binding protein (CREB), an extensively studied transcription factor required for activitydependent gene expression and L-LTP (Kandel, 2001; Lonze and Ginty, 2002; Silva, 2003). Furthermore, the PAK3 knock-out mice showed accelerated extinction of the hippocampusindependent (implicit) taste aversion associative learning task, whereas their hippocampus-dependent (explicit) spatial memory was not affected. These results indicate a novel role for Rho signaling in the regulation of CREB function and synaptic plas- 
ticity and suggest that abnormal CREB function may contribute to the pathogenic process of MRX.

\section{Materials and Methods}

Generation of PAK3 knock-out mice. To create PAK3 knock-out mice, a 10 $\mathrm{kb}$ DNA fragment was isolated from the $129 \mathrm{sv}$ genomic library and the exon containing the 166 base pair coding sequence immediately before the kinase domain was sequenced and confirmed to be identical to the published mouse PAK3 cDNA. A targeting vector was constructed by replacing a part of the coding and adjacent downstream intronic sequence by a pgk-neomycin resistant gene cassette (see Fig. 1). The vector was designed to completely eliminate the entire kinase domain of PAK3. The G418-resistant R1 embryonic stem (ES) clones (derived from the 129sc mouse strain) were screened for a targeted event by Southern blot analysis. A probe external to the targeting vector (see Fig. 1) was used for analyzing ES and mouse tail DNA. Two positive ES clones were used to generate chimeric mice by aggregation. The chimeras were crossed to C57/BL6 to generate an F1 population. The PAK3 knock-out offspring $(\mathrm{PAK} 3-)$ and their wild-type littermates $(\mathrm{PAK} 3+)$ from the F1 interbreeding were used in this study. Some experiments were confirmed using offspring from F1 interbreedings with a CD1 genetic background (i.e., CD1 mice were used for initial breedings with the chimeras to generate a separate $\mathrm{F} 1$ population).

Histology, immunoblot, immunostaining, Golgi staining, and electron microscopy. The procedures for histology, Golgi staining, and electron microscopy of fixed brain tissues were described previously (Jia et al., 1996; Meng et al., 2002). Cultured hippocampal or cortical neurons were prepared and maintained according to a procedure recommended for Neurobasal-A medium (Invitrogen, San Diego, CA). For filamentous actin (F-actin) labeling, fixed cells were permeabilized with $0.1 \%$ Triton X-100/PBS and stained for $30 \mathrm{~min}$ with $1 \mu \mathrm{g} / \mathrm{ml}$ tetramethylrhodamine isothiocyanate (TRITC)-conjugated phalloidin (Sigma, St. Louis, MO). The intensity of phalloidin fluorescence was measured and compared using a Northern Eclipse program (Toronto) as described previously (Meng et al., 2002). The intensity of the entire spine head (ranging from 0.3 to $1.0 \mu \mathrm{m}$ in diameter) was measured and subtracted (or divided to obtain spine/dendrite ratio) by that of an adjacent dendritic area of a similar size below the neck. These measurements revealed no significant differences between PAK3 knock-out and the wild-type control neurons. For immunostaining for PAK3 or microtubule-associated protein 2 (MAP2), fixed cells were permeabilized for $10 \mathrm{~min}$ with cold methanol, blocked for $1 \mathrm{~h}$ with $5 \%$ BSA, and then incubated with appropriate primary and then secondary antibodies followed by TRITC-conjugated phalloidin staining.

Cofilin, CREB, mitogen-activated protein kinase, Akt, and protein kinase A phosphorylation assay. Protein lysates from whole-brain or hippocampal slices were used to estimate the amount of phosphorylated forms of actin depolymerizing factor (ADF)/Cofilin, CREB, mitogen-activated protein kinase (MAPK) P44/42, P38, c-Jun N-terminal protein kinase (JNK), Akt, and protein kinase A (PKA) (see Fig. 5) with antibodies specific for phospho-Cofilin (Santa Cruz Biotechnology, Santa Cruz, CA), phospho-CREB (s.c.-7978; Santa Cruz Biotechnology), phosphoP44/42 (Cell Signaling Technology, Beverly, MA), phospho-JNK, phospho-P38 (Cell Signaling Technology), phospho-Akt (Upstate Biotechnology, Lake Placid, NY), and phospho-PKA (Upstate Biotechnology), respectively. Other primary antibodies used in this study include the following: anti-MAP2 (Upstate Biotechnology), anti-GluR2/3 (Chemicon, Temecula, CA), anti-PAK1 (Santa Cruz Biotechnology), anti-PAK2 (Santa Cruz Biotechnology), anti-PAK3 (Santa Cruz Biotechnology), anti-Cofilin (Cytoskeleton), anti-CREB (06-863; Upstate Biotechnology), anti-Rho-associated kinase 2 (ROCK2; Santa Cruz Biotechnology), and anti-phospho-PAKs (Cell Signaling Technology). The procedures and conditions for preparing and maintaining hippocampal and brain slices were the same as those used for electrophysiological recordings (see below) to compare biochemical and recording data. Under these conditions, the levels of both phosphorylated and total proteins analyzed in this study remained stable during the course of the experiments (up to $6 \mathrm{~h}$ ). For each experiment, protein samples (10 $\mu \mathrm{g}$ of total proteins) of each genotype were loaded on SDS gel (samples from PAK3 knock-out mice were always loaded side by side with those from the wild-type littermate for better comparisons) and analyzed with Western blot analysis. The amount of each protein detected by the enhanced chemiluminescence (Amersham Biosciences, Piscataway, NJ) method was estimated by scanning optical density of the blot, and the averaged normalized data were evaluated with the Student's $t$ test. In the experiments presented in Figure 5, $n$ represents the number of independent experiments.

Electrophysiology. All electrophysiological recordings were conducted at the Schaffer/Collateral pathway in the hippocampus (Meng et al., 2002, 2003b). For LTP studies, the mice ranged from 2 to 4 months of age and, for long-term depression (LTD) and whole-cell patch clamping, from 2 to 5 weeks of age. The extracellular solution contained the following (in mM): $120 \mathrm{NaCl}, 2.5 \mathrm{KCl}, 1.3 \mathrm{MgSO}_{4}, 1.0 \mathrm{NaH}_{2} \mathrm{PO}_{4}, 26 \mathrm{NaHCO}_{3}$, $2.5 \mathrm{CaCl}_{2}$, and $11 \mathrm{D}$-glucose. For field EPSPs (fEPSPs), the recording pipette $(3 \mathrm{M} \Omega)$ was filled with extracellular solution. For whole-cell voltage-clamp recordings, the patch pipette (3-5 M $\Omega$ ) contained the following (in mM): 132 Cs gluconate, $17.5 \mathrm{CsCl}$, 0.05 EGTA, 10 HEPES, 2 Mg-ATP, $0.2 \mathrm{Na}-\mathrm{GTP}$, and $\mathrm{N}$-ethyl bromide quaternary salt, $\mathrm{pH} 7.4$, (292 mOsm). All data acquisition and analysis were done using pClamp 7 software (Molecular Devices, Union City, CA). In Figures 3 and 4, $n$ represents the number of hippocampal slices, and only one slice from each animal was used. All averaged recording data were statistically evaluated by Student's $t$ test. Error bars presented are SEM.

Mice for behavioral tests. A total of 22 male mice $\left(N_{\text {Pak3- }}=11\right.$; $N_{\text {Pak3+ }}=11$; from six litters) between 5.8 and 6 months of age at the onset of behavioral experiments were used for behavioral tests. The mice of both genotypes did not differ in their body weight either at the onset $(35.9 \pm 1.7 \mathrm{~g}$ and $39.8 \pm 2.2 \mathrm{~g}$ for PAK3 + and PAK3 - mice, respectively; $\left.t_{(19)}=-1.4 ; p>0.05\right)$ or at the completion $(35.3 \pm 1.2 \mathrm{~g}$, PAK3+; $36.3 \pm 1.7 \mathrm{~g}$, PAK3 $\left.-; t_{(19)}=-0.5 ; p>0.05\right)$ of the study. They were housed in groups of two to four during water maze experiments and singly in a cage during a conditioned taste aversion (CTA) test under standard laboratory conditions $(12 \mathrm{~h} \mathrm{light/dark} \mathrm{cycle} \mathrm{with} \mathrm{lights} \mathrm{on} \mathrm{at}$ 6:00 A.M.) with a room temperature of $21^{\circ} \mathrm{C}$. Water and food were available ad libitum unless otherwise indicated. All experimental manipulations and tests were performed during the light phase of the cycle (between 9:00 A.M. and 2:00 P.M.) in accordance with institutional and Canadian Council on Animal Care guidelines. The mice were given a battery of behavioral tests in the following sequence: a reference memory version of the Morris water maze test (MWM), a cued (visible) platform MWM test, and a conditioned taste aversion test. Before behavioral experiments commenced, all mice were handled twice daily.

Water maze test. The water maze apparatus and general methodology were described in detail previously (Janus, 2004). Briefly, it consisted of a circular pool ( $1.5 \mathrm{~m}$ in diameter and $0.30 \mathrm{~m}$ in height $)$ made of white plastic, which was elevated $86 \mathrm{~cm}$ from the floor level. The pool was filled to a depth of $17 \mathrm{~cm}$ with water $\left(24-25^{\circ} \mathrm{C}\right)$ that was made opaque by the addition of nontoxic white paint. An escape platform $(13 \mathrm{~cm}$ in diameter) made of white plastic with grooved surface was submerged $0.5-1.0$ $\mathrm{cm}$ under the water level. During a visible platform or cued-response training, the platform was fitted with a centrally mounted post $(10 \mathrm{~cm}$ in height, $1 \mathrm{~cm}$ in diameter), which was painted with black and white horizontal stripes and fitted with a $2.5 \mathrm{~cm}$ white ball on the top. During probe trials, the platform was removed from the pool. The pool was situated in an experimental room $(3.6 \times 4.6 \mathrm{~m})$ containing three cage racks. One of the racks divided the room into a $3 \times 3 \mathrm{~m}$ testing area and a small annex housing recording equipment. Dark posters and a small $(40 \mathrm{~W})$ light in one corner provided additional distant landmarks in the room. The search path of a mouse in a trial was recorded by a camera connected to a video-tracking system (HVS Image Advanced Tracker VP200; HVS Image, Buckingham, UK) and a personal computer running HVS software. The following measures were used to assess learning acquisition: escape latency $(\mathrm{s})$, swim path $(\mathrm{m})$, and speed $(\mathrm{m} / \mathrm{s})$, cumulative search error (Gallagher et al., 1993), and percentage of time dwelling in the outer $(0.2 \mathrm{~m})$ zone of the pool. The spatial memory for the platform location during probe trials was evaluated by the analysis of the dwelling time in 
A

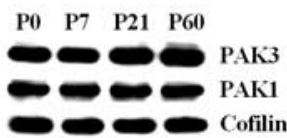

B

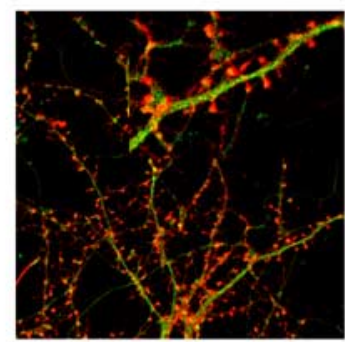

C

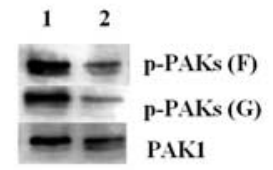

D

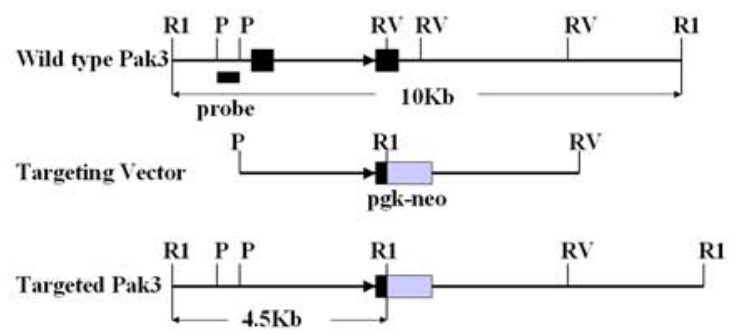

$\mathbf{E}$

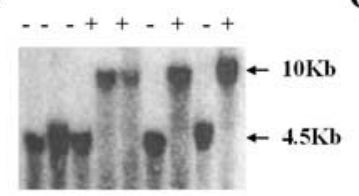

F

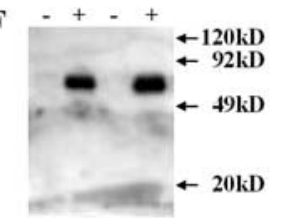

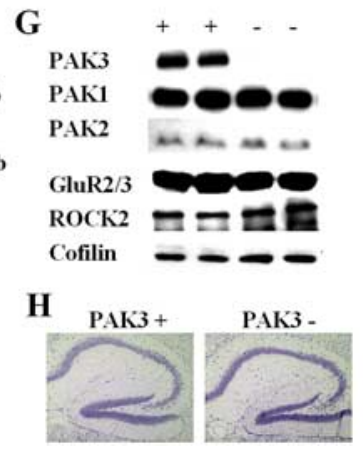

Figure 1. Expression of PAK3 and generation of PAK3 knock-out mice. $A$, Western blot analysis of total brain lysates showing the expression of PAK1 and PAK3 at various postnatal stages [postnatal day 0 (P0) to P60]. Results are representative of three independent Western blot experiments for each antibody ( 3 animals for each age group). $\boldsymbol{B}$, Cultured hippocampal neurons (20 DIV) stained with anti-PAK3 and F-actin dye phalloidin showing a predominant expression of PAK3 protein in the dendrites. $C$, Western blot analysis of total proteins from cultured cortical neurons (20 DIV) treated with (1) or without (2) glutamate (50 $\mu \mathrm{M}_{\text {, }}$ 10 min; $\mathrm{p}$-PAKs-G) or forskolin (10 $\mu \mathrm{m}, 10 \mathrm{~min}$; $\mathrm{p}$-PAKs-F) showing increases in phosphorylated (active) PAKs by these treatments. Results are representative of two independent experiments for each antibody. $D$, Schematic representation of the wild-type Pak3 locus, the targeting vector, and the targeted Pak3 locus. The solid boxes indicate the exons that are contained in the genomic clone used for vector construction. P, Pstl; R1, EcoRl; RV, EcoRV. E, Southern blot analysis of tail DNA prepared from male F1 offspring showing the wild-type ( $10 \mathrm{~kb}$ ) and targeted (4.5 kb) Pak3 gene (note that the Pak3 gene is $X$ chromosome linked, and only one copy is present in males). $\boldsymbol{F}, \boldsymbol{G}$, Western blot analysis of total brain lysate with anti-PAK3 showing the absence of PAK3 protein $(\boldsymbol{F})$ but normal levels of PAK1, GluR2/3, ROCK2, and Cofilin in PAK3 knock-out mice (G). $\boldsymbol{H}$, Nissl staining of fixed brain sections showing normal hippocampal formation in PAK3 knock-out mice.

each of the quadrants of the pool, the number of swims over the platform site in the target quadrant (TQ), and an annulus crossing index (ACI). The ACI represents the number of crosses over the platform site in a quadrant, which contained the escape platform (TQ) adjusted for crosses over platform sites in alternative quadrants (i.e., ACI is equal to the number of site crosses in TQ minus an average of crosses of sites in the other three quadrants of the pool). ACI represents an unbiased evaluation of spatial memory in the water maze test controlling for nonspatial search strategies (Janus, 2004). Experimentally naive mice were given five daily sessions with four $90 \mathrm{~s}$ training trials per session. An escape platform was always positioned in the center $(37.5 \mathrm{~cm}$ from the wall) of the Northeast quadrant of the pool (TQ). A mouse was carried to the pool in a holding container and was released into water facing the wall of the pool. After locating and climbing onto a platform, a mouse was allowed $10 \mathrm{~s}$ of posttrial time, after which it was removed from the pool using a wire mesh spatula. If a mouse did not find a platform within an allocated time, it was guided to it using a white pointer with a $5 \mathrm{~cm}$ black tip and was allowed $10 \mathrm{~s}$ of posttrial time on a platform. An orientation of mice to a pointer was used as additional evaluation of their visual acuity and responsiveness to a cue. After each trial, the mouse was returned to the holding cage placed under a heat lamp. All mice were tested in squads, with an intertrial interval of $\sim 40 \pm 10 \mathrm{~min}$. Two $60 \mathrm{~s}$ probe trials were administered to evaluate the development of spatial memory for the platform location. The first probe trial was administered after $2 \mathrm{~d}$ of training as a first trial on day 3 , and the second probe trial was given $24 \mathrm{~h}$ after the completion of training on day 6. During reversal of learning tests, an escape platform was moved to the Northwest quadrant $(31 \mathrm{~cm}$ from the wall of the pool) during the first three training sessions and to the Southeast quadrant $(38 \mathrm{~cm}$ from the wall) for the remaining two sessions. Placing an escape platform at various distances from the wall in each series of reversal training prevented mice from using a nonspatial chaining strategy to solve the spatial task (Janus, 2004).

Conditioned taste aversion test. Three days before the onset of an experiment, mice were transferred to individual cages in which they had ad libitum access to food but restricted (from 9:00 A.M. to 4:00 P.M.) access to water presented in two $15 \mathrm{ml}$ bottles. Water intake during the first 30 min drinking interval (9:009:30 A.M.) was recorded separately. At the end of a $6 \mathrm{~d}$ adaptation phase, mice reliably consumed $>1 \mathrm{ml}$ of water during the initial $30 \mathrm{~min}$ interval. Under this water-deprivation regimen, mice maintained body weight at $\sim 95.6 \pm 2.0 \%$ of the pre-experimental value of $37.8 \pm 1.4 \mathrm{~g}$. To acclimatize mice to sweet taste, all mice were given an exposure to $0.5 \%$ saccharine solution (2,3-Dihydro-3-oxobenzisosulfonazole; Sigma) provided in one of the two $15 \mathrm{ml}$ bottles during the 30 min drinking session over four consecutive days. On the conditioning day, all mice were exposed to a grape-flavored saccharin solution $(0.05 \% \mathrm{w} / \mathrm{w}$ Kool-Aid in $0.5 \% \mathrm{sac}$ charine) [conditioned stimulus (CS)] provided in one $15 \mathrm{ml}$ bottle during the 30 min drinking session. One hour later, the mice were injected intraperitoneally with lithium chloride ( $\mathrm{LiCl}$; $0.14 \mathrm{M} ; 2 \%$ body weight) as a nausea-inducing agent [unconditioned stimulus (US)]. Behavioral signs of malaise (unconditioned response), such as "lying-on-belly" (Meachum and Bernstein, 1990; Stafstrom-Davis et al., 2001), "freezing," "chin rubbing" (Smith and Parker, 1995), and other behaviors such as grooming, locomotion, and eating were recorded for $20 \mathrm{~min}$ after $\mathrm{LiCl}$ administration using an instantaneous sampling method (sample intervals of $30 \mathrm{~s}$ ). Four and one-half hours after CS-US (between 2:00 and 2:30 P.M.), the mice were given a two-bottle, short-term memory (STM) choice test between water presented in one bottle and grape-flavored saccharine solution presented in another bottle. Placement of saccharine bottles with reference to the water bottles was random. Grape solution intake was expressed as the percentage of grape solution consumed of the total fluid intake: $\mathrm{ml}$ of grape/ $(\mathrm{ml}$ of water $+\mathrm{ml}$ of grape $)^{\star} 100$. The long-term memory tests were administered on days 13-16 after the CS-US pairing. To determine the basic taste sensitivity and unconditioned taste aversion to a bitter tasting substance, PAK3 - mice and PAK3 + littermates were given a 30 min two-bottle choice test with a quinine solution (quinine monohydrochloride dihydrate $90 \%$ at a concentration of $0.02 \%$; Sigma-Aldrich) in one bottle and water in another bottle $33 \mathrm{~d}$ after conditioning.

Behavioral data analysis. A factorial model ANOVA with the genotype (PAK3 - vs PAK3 + littermates) as between subjects, and days of training or testing as within-subject (repeated-measure) factors was used in the analysis of data. While performing all repeated-measures ANOVAs, departures from the assumption of compound sphericity were evaluated by the Mauchly sphericity test [SPSS (Chicago, IL) statistical package v.11.0.2 run on a Macintosh computer (Apple Computers, Cupertino, CA)] with $\alpha$ level set to 0.05 . In cases in which sphericity was significantly violated, degrees of freedom were adjusted by Greenhouse-Geisser $\epsilon$-correction. When appropriate, the comparisons of performance or body weight at single time points were performed using the Student's $t$ test. The critical $\alpha$ level was set to 0.05 for all statistical analyses. Because of space limitation, only the significant results pertaining to tested hypotheses were reported. 


\section{Results}

Expression and activation of PAK 3 in the hippocampus

To address the in vivo function of PAKs, we first analyzed their expression pattern in the mouse brain. Western blot analysis of whole-brain lysate showed that PAK3 as well as PAK1 was expressed in both the developing and the adult brain (Fig. $1 A$ ). A similar result was obtained using isolated hippocampal protein lysate (data not shown). To specifically examine the subcellular distribution of PAK3, we performed double immunostaining for PAK3 and F-actin using cultured hippocampal neurons. As shown in Figure $1 B$, PAK3 was predominantly expressed in the soma and throughout the dendrites but was essentially absent in the dendritic spine. To test whether PAKs can be activated by neuronal activity, we treated cultured hippocampal neurons with glutamate or forskolin (to activate protein kinase A) and analyzed the level of PAK phosphorylation at Thr-423 (an activation indicator of PAKs, including PAK3). Both treatments significantly increased the amount of phosphorylated PAKs (Fig. 1C), indicating that PAKs can be activated by glutamate receptors. These results, together with previous studies (Manser et al., 1994, 1995; Boda et al., 2002; Ong et al., 2002; Kohn et al., 2004), suggest that PAK3 may play an important role in the regulation of hippocampal neuronal and synaptic function.

\section{Normal brain anatomy in PAK3 knock-out mice}

To further investigate the in vivo role of PAK3 and because of the lack of pharmacological inhibitors specific for PAK3, we generated and analyzed knock-out mice deficient in the expression of PAK3 (Fig. 1D,E). The targeting strategy was designed to completely abolish the expression of the kinase domain of PAK3 to mimic human MRX conditions in which the Pak3 mutations appeared to lead to a loss of PAK3 protein function (Jia et al., 1996; Allen et al., 1998; Chelly and Mandel, 2001). Only male PAK3 knock-out offspring (PAK3-) and their wild-type littermates $(\mathrm{PAK} 3+)$ derived from $\mathrm{F} 1$ breedings were used in the present study. The knock-out mice showed no detectable amount of PAK3 protein, but the expression of its closest family member PAK1, PAK2, and other neuronal proteins, including Rhoassociated kinase, ROCK2, and glutamate receptors was not affected (Fig. $1 F, G$ ). Histological analysis of fixed-brain sections showed no detectable abnormalities in the gross anatomy of the CNS, including hippocampus and cerebellum (Fig. $1 \mathrm{H}$ ). The knock-out mice also showed no apparent changes in viability, lifespan, fertility, or home-cage locomotor activities assessed by daily behavioral observations. These results are consistent with human MRX patients with Pak3 mutations or other types of nonsyndromic MRX in which no apparent changes in the gross anatomy of the CNS were found (Allen et al., 1998; Chelly and Mandel, 2001). $A g, A h$, insets, $2 \mu \mathrm{m}$
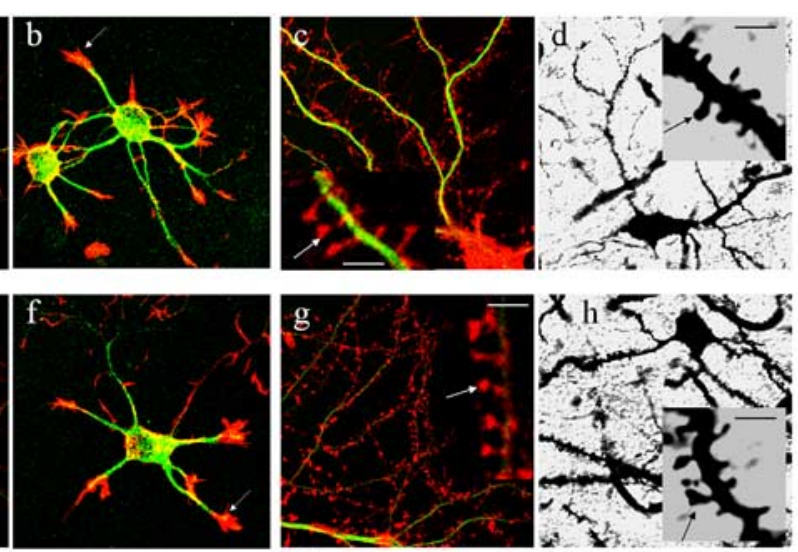

C

D
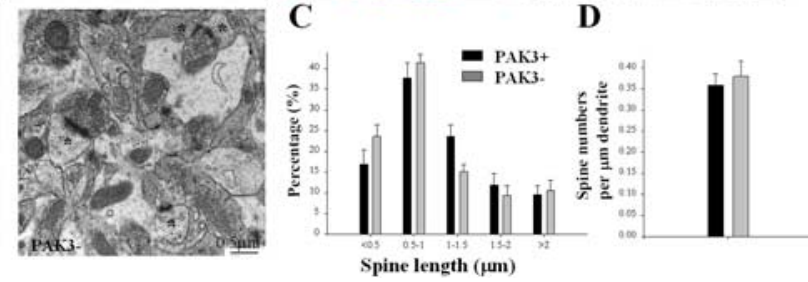

Figure 2. Dendritic spines and synaptic structures in PAK3 knock-out mice. Cultured hippocampal neurons stained with

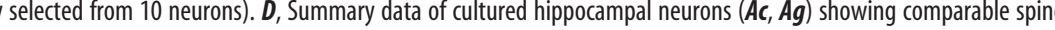

\section{Normal dendritic and spine morphology in PAK3 knock-out mice}

In culture systems, perturbations of Rho signaling, including PAKs, affect various neuronal structures, including dendritic branches and spines (Luo, 2000, 2002; Nakayama et al., 2000; Tashira et al., 2000; Ishikawa et al., 2003; Boda et al., 2004; Govek et al., 2004; Hayashi et al., 2004). We therefore examined the morphology of cultured hippocampal neurons prepared from PAK3 knock-out mice (Fig. 2). First, we compared the complexity of the dendrites by analyzing the dendritic marker MAP2 staining and found no significant differences in either the number or the total length of the dendrites between PAK3 knock-out and wild-type neurons (Fig. $2 A a, A e$ ). Similar results were obtained in relatively young neurons [ $5 \mathrm{~d}$ in vitro (DIV)], in which the morphology of actin-rich growth cones appeared to be normal in the knock-out neurons (Fig. 2Ab,Af). We then analyzed spine properties by analyzing F-actin dye phalloidin-stained neurons but found no differences in either spine density or spine length between genotypes, although there was a small but not significant increase in the number of spines shorter than $1 \mathrm{~mm}$ in the knock-out mice (Fig. $2 A c, A g, C, D$ ). Golgi staining of fixed brain sections also showed no significant alterations in either spine density $(\mathrm{PAK} 3+, 0.57 \pm 0.04$ spines $/ \mu \mathrm{m}$; PAK3,$- 0.48 \pm$ 0.03 spines $/ \mu \mathrm{m} ; p=0.07$; a total of $850 \mu \mathrm{m} \mathrm{PAK} 3+$ and $780 \mu \mathrm{m}$ $\mathrm{PAK} 3-$ dendritic fragments from three brain sections were analyzed) or spine length (PAK3 $+, 0.5-2 \mu \mathrm{m}, 95 \pm 1 \%$ and $>2 \mu \mathrm{m}$, $5 \pm 1 \%$; PAK3 - , 0.5-2 $\mu \mathrm{m}, 96 \pm 1 \%$ and $>2 \mu \mathrm{m}, 4 \pm 1 \%, p=$ 0.6 ; a total of $375 \mathrm{PAK} 3+$ and $363 \mathrm{PAK} 3-$ spines from three brain sections were used for the analysis) in the knock-out mice 
A

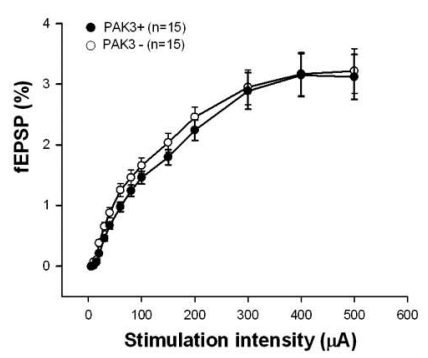

D

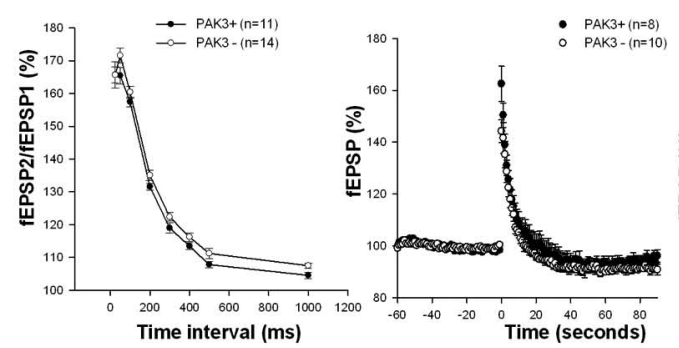

$\mathbf{B}$

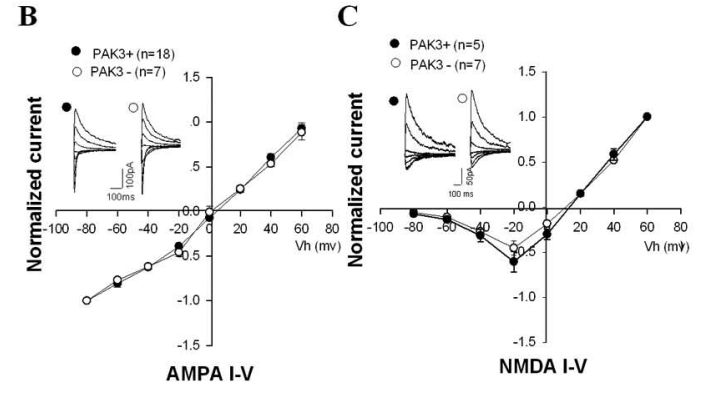

F

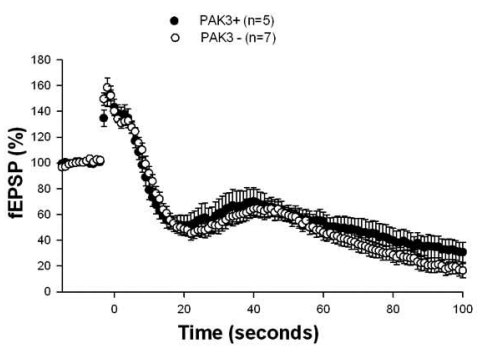

Figure 3. Normal basal synaptic function in PAK3 knock-out mice. $\boldsymbol{A}$, fEPSP slopes as a function of stimulation intensities. $\boldsymbol{B}, \boldsymbol{C}$, Averaged amplitudes of evoked AMPA receptor-mediated $(\boldsymbol{B})$ or NMDA receptor-mediated $(\boldsymbol{C})$ EPSC s recorded from CA1 pyramidal neurons showing no differences between the wild-type and PAK3 knock-out mice. AMPA currents were estimated 5 ms after stimulation in the presence of $100 \mu \mathrm{m}$ picrotoxin and normalized to the EPSC at $-60 \mathrm{mV}$. The NMDA currents were measured with peak amplitudes in the presence of $100 \mu \mathrm{m}$ picrotoxin and $10 \mu \mathrm{M}$ CNQX and normalized to the EPSC at $+60 \mathrm{mV}$. The representative traces at various holding potentials were averages of four successive sweeps. $\boldsymbol{D}$, Normal PPF as a function of interpulse interval. $\boldsymbol{E}$, Normal posttetanic potentiation in response to $100 \mathrm{~Hz}(1 \mathrm{~s})$ high-frequency stimulation. The recording was performed in the presence of $50 \mu \mathrm{m}$ D-AP-5. F, Normalized fEPSPs as a function of stimulation time showing normal synaptic depression in response to repetitive stimulation $(10 \mathrm{~Hz} ; 100 \mathrm{~s})$ in the knock-out mice.

(Fig. $2 A d, A h$ ). Moreover, synaptic structures, including postsynaptic density and presynaptic transmitter vesicles, appeared to be normal (Fig. 2 B). These results indicate that neuronal and synaptic structures were not significantly affected by the absence of PAK3.

\section{Normal basal synaptic strength in PAK3 knock-out mice}

We then went on to examine the properties of synaptic physiology by recording synaptic responses in the CA1 region of the hippocampus. First, we assessed the basal synaptic strength by analyzing fEPSPs and prefiber volley evoked by various stimulation intensities and found no differences between PAK3 knockout and the wild-type mice (Fig. 3A). Similarly, whole-cell voltage-clamp recordings from CA1 pyramidal neurons showed no differences in either the amplitude or current-voltage relationship of EPSCs mediated by AMPA (Fig. 3B) or NMDA (Fig. $3 C)$ glutamate receptors. To examine presynaptic function, we compared paired-pulse facilitation (PPF), posttetanic potentiation, and the extent of neurotransmitter depletion in response to sustained high-frequency stimulation (HFS) and found no significant differences between the knock-out and wild-type mice (Fig. 3D-F). These results indicate that basal synaptic strength and presynaptic neurotransmitter release are not significantly altered in PAK3 knock-out mice, consistent with normal spine and synaptic structures in the knock-out mice.

\section{Selective deficits in L-LTP in PAK3 knock-out mice}

We further investigated the properties of synaptic function by comparing synaptic plasticity, specifically long-term potentiation and LTD, the most extensively studied forms of synaptic plasticity thought to be important for learning and memory (Bliss and Collingridge, 1993; Bear and Abraham, 1996; Malenka and Nicoll, 1999). In the CA1 region of the hippocampus, two distinct forms of LTP can be induced depending on the pattern of conditioning protocols: a relatively short-lasting or early phase LTP (E-LTP) induced by a single train of HFS ( $100 \mathrm{~Hz}$ lasting for $1 \mathrm{~s}$ ) and a long-lasting or late phase LTP induced by multiple trains of HFS (Kandel, 2001). As shown in Figure 4, whereas hippocampal LTD induced by low-frequency stimulation ( $1 \mathrm{~Hz}$ for $15 \mathrm{~min})(64.37 \pm 3.65 \%$ for $\mathrm{PAK} 3+; 64.91 \pm 2.22 \%$ for PAK3 $-; p=$ $0.36)$ and E-LTP $(145.55 \pm 6.08 \%$ for $\mathrm{PAK} 3+; 139.06 \pm 2.28 \%$ for PAK3 $-; p=$ 0.29 ) were not altered (Fig. $4 A, B$ ), L-LTP induced by three trains of HFS (Fig. 4C) was significantly reduced in the knock-out mice $(151.19 \pm 7.19 \%$ for $\mathrm{PAK} 3+$; $119.77 \pm 6.56 \%$ for PAK3 $-; p=0.007)$. Therefore, PAK3 knock-out mice are selectively impaired in long-lasting synaptic plasticity.

\section{Reduction in phosphorylated CREB in PAK3 knock-out mice}

To elucidate the molecular mechanisms underlying this reduced long-lasting synaptic plasticity in PAK3 knock-out mice, we analyzed the expression and function of a number of proteins or cellular processes thought to be important for L-LTP. Activity-dependent actin reorganization is required for the structural remodeling at the synapse, a process believed to contribute to the long-lasting nature of L-LTP (Fukazawa et al., 2003; Lisman, 2003; Okamoto et al., 2004; Zito et al., 2004). A key mechanism by which PAKs exert their effects on actin dynamics in the hippocampus is through regulating the activity of LIM (the three gene products Lin-11, Isl-1, and Mec-3) kinase (LIMK) to phosphorylate and inactivate ADF/Cofilin (Meng et al., 2002, 2003a; Bokoch, 2003; Lisman, 2003; Okamoto et al., 2004; Zhao and Manser, 2005). Therefore, we compared the levels of total and phosphorylated (or inactive) ADF/Cofilin but found no significant differences between the knock-out and wild-type mice (Fig. 5A). These results were consistent with the observation that actin filaments appeared to be distributed normally in dendritic spines and growth cones of PAK3 knock-out neurons (Fig. 2) and suggested that the synaptic deficits in PAK3 knock-out mice are not likely related to the actin cytoskeleton or neuronal structures. Because PAKs can affect a number of protein kinases, including MAPK, PI 3-kinase/Akt, and PKA, all of which have been shown to be important in controlling hippocampal synaptic plasticity, including L-LTP (Impey et al., 1998; Perkinton et al., 2002; Bokoch, 2003; Thomas and Huganir, 2004; Zhao and Manser, 2005), we examined the activity of these proteins. Analysis of phosphorylated (or active) MAPK P44/42, P38, and JNK showed no significant differences between the knock-out and wild-type mice, indicating that the MAPK signaling was not significantly perturbed in the knock-out mice (Fig. 5A). Similarly, no differences were found in the amount of phosphorylated Akt and PKA (data not shown). Finally, we examined CREB activity by specifically comparing the 
A

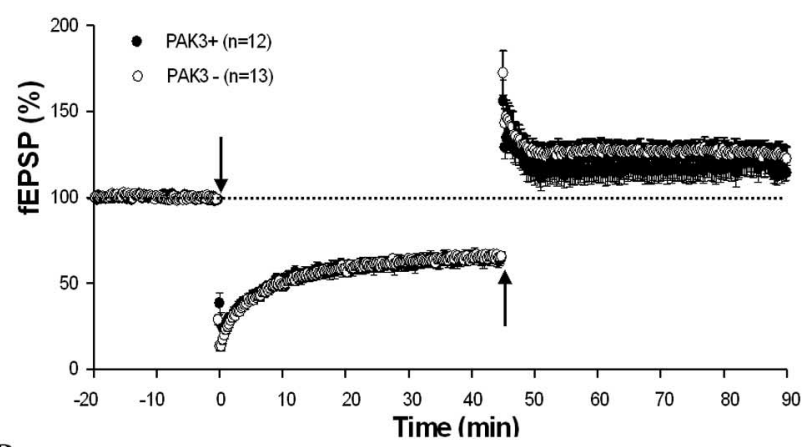

B

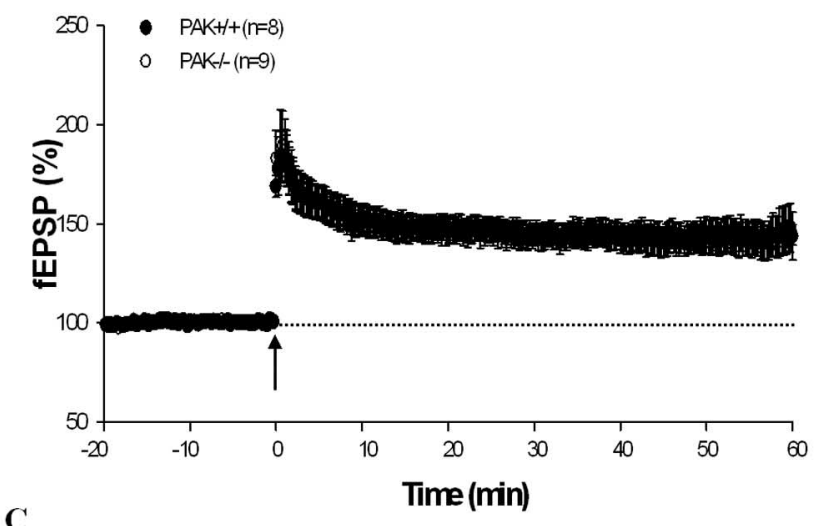

C

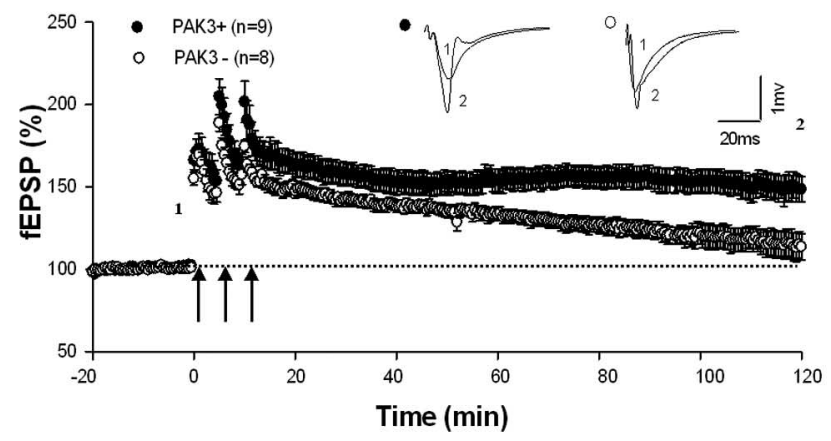

Figure 4. Impaired L-LTP in PAK3 knock-out mice. $A$, Normal hippocampal LTD induced by 1 $\mathrm{Hz}$ stimulation (lasting $15 \mathrm{~min}$; downward arrow) and depression induced by $100 \mathrm{~Hz}$ stimulation (1 s; upward arrow). B. Hippocampal LTP induced by a single train of $100 \mathrm{~Hz}$ (1 s; upward arrow) was indistinguishable between the wild-type and PAK3 knock-out mice. C, L-LTP induced by three trains of $100 \mathrm{~Hz}$ stimulation (upward arrows) was significantly reduced in PAK3 knock-out mice.

amount of phosphorylated CREB at Ser-133. Ample evidence indicates that CREB and stimulus-induced CREB Ser-133 phosphorylation are required for L-LTP and memory formation (Kandel, 2001; Lonze and Ginty, 2002; Silva, 2003). As shown in Figure $5 B$, whereas the total protein level of CREB was not altered, the amount of phosphorylated CREB Ser-133 was dramatically reduced in the knock-out mice. This reduction occurred both in the cortex and in the hippocampus. To further investigate whether there were any changes in activity-dependent CREB function, we treated hippocampal slices with PKA activator forskolin but found no significant differences between genotypes (Fig. 5C).
A

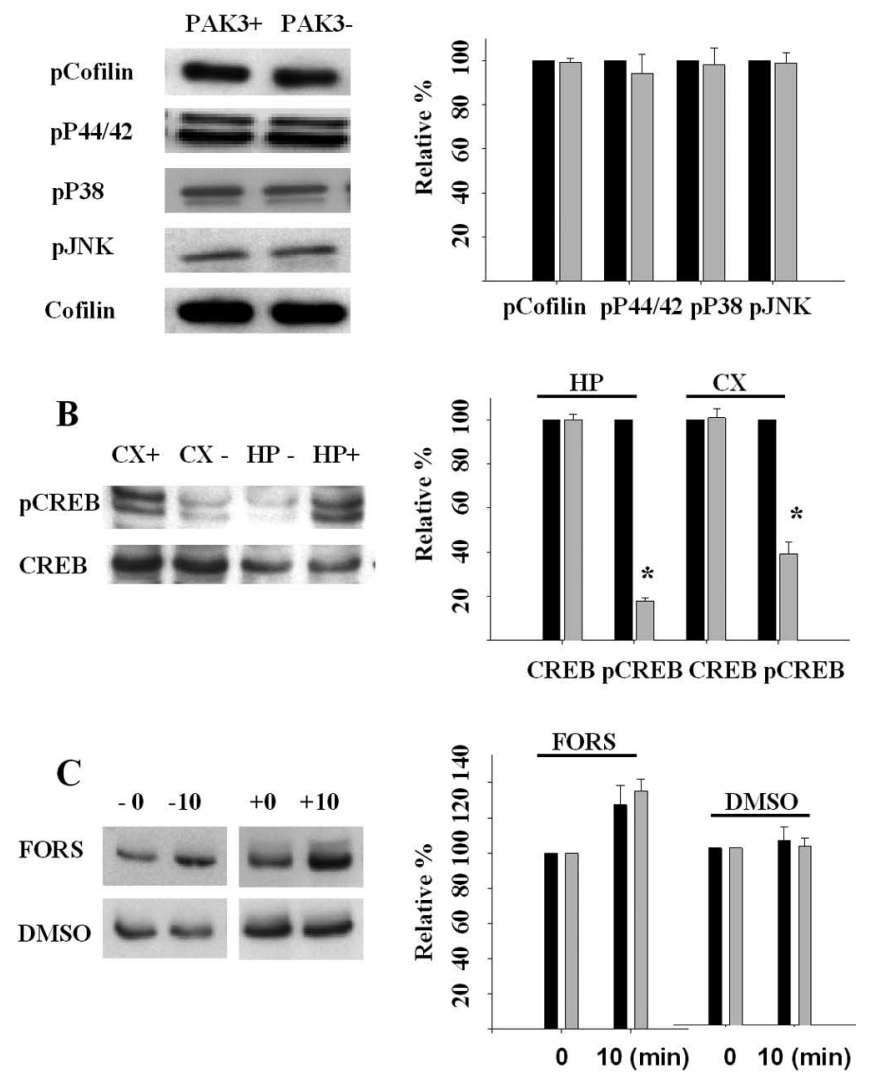

Figure 5. Reduced CREB Ser-133 phosphorylation in PAK3 knock-out mice. $\boldsymbol{A}$, Examples (left) and summary data (right; normalized to respective wild-type levels) of Western blot analysis of phosphorylated forms of various MAP kinases ( $\mathrm{p}-\mathrm{P} 44 / 42, n=8, p=0.58 ; \mathrm{p}-\mathrm{P} 38$, $n=5, p=0.43 ; p$-JNK, $n=6, p=0.84$ ) and Cofilin ( $p$-Cofilin; $n=6 ; p=0.95$ ) showing normal MAP kinase and Cofilin activities in PAK3 knock-out mice. $\boldsymbol{B}$, Reduced phosphorylated CREB-Ser133 in the knock-out mice. Examples (left) and summary of normalized data (right) of Western blot analysis of total protein lysates prepared from cortical (CX) or hippocampal (HP) slices showing a reduction of $p$-CREB, but not total CREB, in PAK3 knock-out (CX-, HP-) compared with the wild-type mice $(C X+, H P+)$. Asterisks in the summary data indicate significant differences between the wild-type and knock-out mice in both hippocampus and cortex (HP, $n=6, p<0.001 ;(X, n=6, p<0.001)$. C, Changes in $p$-CREB in response to forskolin treatment. Examples (left) and averages of normalized data (right; the levels of $p$-CREB after 10 min of treatment were normalized to those of respective genotypes without treatment indicated by 0 min) showing no significant differences in the degree of increases in p-CREB induced by forskolin (FORS, $50 \mu \mathrm{m}$; $10 \mathrm{~min}$ ) between the wild-type and knock-out slices ( $n=7$ for each genotype; $p=0.84$ ). DMSO alone treatment (DMSO; $50 \mu \mathrm{m} ; 10 \mathrm{~min}$ ) caused no changes in $p$-CREB in either wild-type or knock-out slices. $n$ represents the number of independent experiments. For each experiment, the protein samples from the wild-type slices were always loaded on an SDS gel side by side with those from the knock-out slices, and the blot was probed only once with a specific antibody. Separate protein samples prepared from different animals were used for independent experiments.

Normal spatial navigation but enhanced extinction of learned taste aversion in PAK3 knock-out mice

To assess the effect of $P a k 3$ gene deletion on the cognitive behavior of the mice, we performed both hippocampus-dependent (explicit) and hippocampus-independent (implicit) associative learning tasks. Hippocampus-dependent spatial learning was assessed in the reference memory version of the Morris water maze test. Both PAK3 knock-out $(n=11)$ and the wild-type littermates $(n=11)$ showed comparable learning acquisition and spatial reference memory in the MWM test as evaluated by the search path length (Fig. 6A). During the probe trial, performed at the end of training on day 6 , the mice of both genotypes crossed the 
$\mathbf{A}$

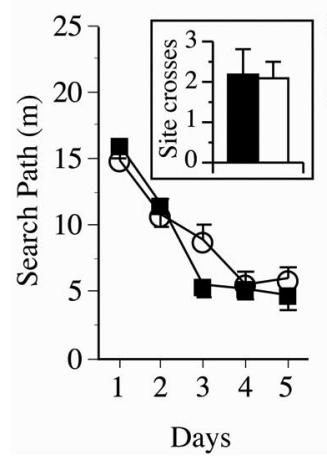

B

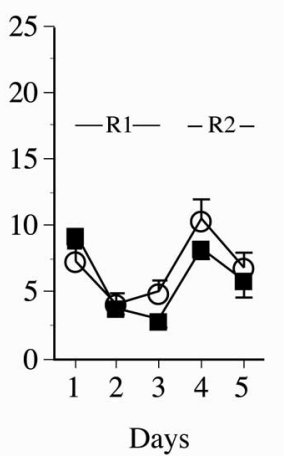

Figure 6. Hippocampus-dependent, explicit spatial reference memory in PAK3 knock-out mice. $\boldsymbol{A}$, In the reference memory version of the MWM task, the PAK3 knock-out mice showed a search path comparable with their wild-type littermates for a hidden escape platform across all five training days. Mice of both genotypes had a comparable spatial memory for an escape platform location during a probe trial (no platform present) administered on day 3 (data not shown) and on day 6 (inset; site crosses represent the number of swims over the platform site in the target quadrant during the probe trial administered on day 6 ). $\boldsymbol{B}$, The acquisition of spatial information by PAK3 knock-out mice was also comparable with their wild-type littermates in a subsequent series of two learning reversals. During the first $3 \mathrm{~d}$ of learning reversal training (R1), the platform location was moved to the Northwest quadrant and, during the remaining $2 \mathrm{~d}$, to the opposite Southeast quadrant. Both genotypes improved their search path during R1, although the shallower learning curves are likely caused by the carrying-over effect from the first reference memory test. When the escape platform was relocated to the opposite quadrant in R2, all mice demonstrated a comparable increase in their search paths in day 4, which decreased in day 5 in comparable manner in both genotypes. C, During a cue (visible platform) test, the knock-out mice ( $n=10 ; 1$ mouse died) did not differ from control mice in their response to a visible cue.

platform location in TQ a comparable number of times (Fig. $6 \mathrm{~A}$, inset) $\left(t_{(20)}=0.12 ; p=0.91\right)$, showing a comparable, positive bias for the platform location (ACI; $0.8 \pm 0.6$ and $1.1 \pm 0.3$, for $\mathrm{PAK}+$ and PAK - mice, respectively; $t_{(20)}=-0.50 ; p=0.62$ ). Furthermore, the results of learning-reversal tests confirmed that the reference memory in the knock-out mice was not compromised (Fig. $6 \mathrm{~B}$ ). Other measures of spatial learning acquisition, including the escape latency and cumulative search error, highly correlated with the search path length $(r=0.75$ and $r=0.85$ for latency and search error, respectively; $p<0.001$ ) and thus are not reported. Both genotypes did not differ in their swim speed, floating rate, thigmotaxic swim (data not shown), or performance in the visible version of the MWM test (one PAK3 - mouse died reducing the sample size to $n=10$ mice) (Fig. $6 C$ ).

Implicit associative learning of the mice was evaluated in a CTA paradigm. In the CTA test, the mice have to learn to avoid a taste of a novel food, which is paired with transiently induced by injection of $\mathrm{LiCl}$ gastrointestinal nausea (US). Pre-exposure to sweet taste of saccharine solution revealed that both genotypes showed a comparable preference for sweet novel taste (Fig. 7A). Both PAK3 knock-out and wild-type mice showed initial neophobic response to the sweet taste, with wild-type mice having a tendency to avoid the novel taste more than the knock-out mice, but after $4 \mathrm{~d}$ of pre-exposure, all mice consumed saccharine at the level of $\sim 80 \%$. Also, both genotypes consumed readily grapeflavored solution of saccharine during a $30 \mathrm{~min}$ CS exposure (Fig. $7 B$ ) and showed a comparable response to $\mathrm{LiCl}$ injection (data not shown). Although, the PAK3 knock-out mice showed a significantly higher intake of CS $(p<0.01)$ (Fig. $7 B)$, the amount of $\mathrm{CS}$ intake during the conditioning session was not correlated with the mice performance in any of the subsequent CTA tests

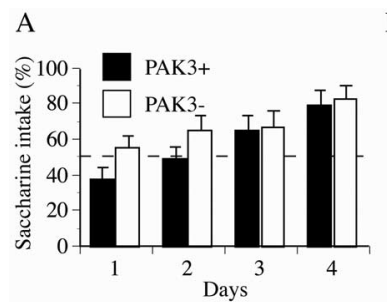

B
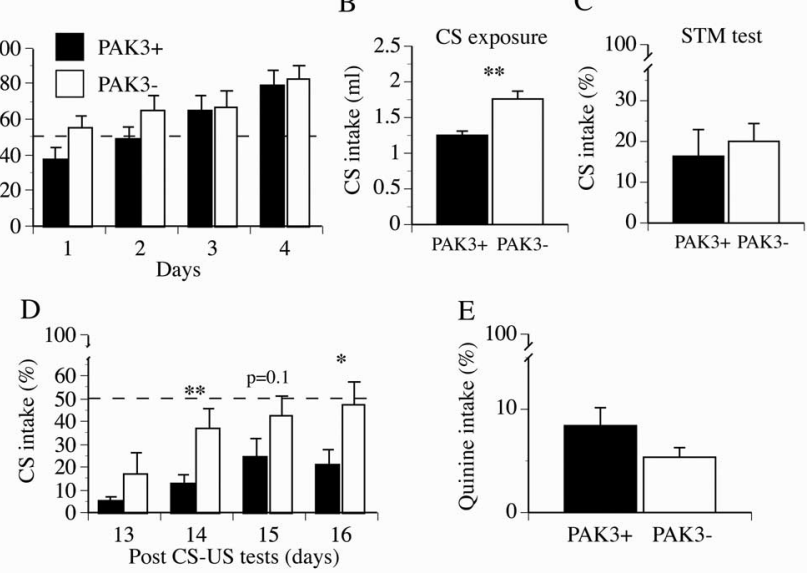

Figure 7. Cognitive abnormalities in PAK3 knock-out mice. $A$, The deletion of Pak3 gene did not affect the preference for a sweet taste in the knock-out mice. Both PAK3 knock-out and wild-type mice, after an initial neophobic response to a novel taste of saccharine solution, showed a steady increase in saccharine consumption during four pre-exposure sessions to $0.5 \%$ saccharine solution. $\boldsymbol{B}$, Mice of both genotypes readily consumed over $1 \mathrm{ml}$ of sweet solution of saccharine flavored with grape during the initial session of $30 \mathrm{~min}$ CS exposure. $\boldsymbol{C}$, STM of learned association between CS and nausea was not affected in PAK3 knock-out mice, because mice of both genotypes avoided the grape solution in a comparable manner in a test performed $4.5 \mathrm{~h}$ after CS-US pairing. D, PAK3 knock-out mice showed a significantly faster extinction rate than the wild-type control $(p<0.02)$ in a series of CTA tests. Pairing of novel taste (grape flavored, $0.05 \%$ saccharine solution; $(S)$ with experimentally induced through intraperitoneal $\mathrm{LiCl}$ injection nausea (US) resulted in a significant avoidance of grape solution (evaluated against $50 \%$ chance level; $p<0.01$ for all test days) by wild-type mice. In contrast, the knockout mice avoided CS solution only during the test on day $13(p<0.01)$, but in later tests, they increased the preference for grape solution and drank it at the chance level. $\boldsymbol{E}$, The basic taste sensitivity of PAK3 knock-out mice was not compromised in PAK3 knock-out mice, because both genotypes avoided a bitter taste of $0.02 \%$ quinine solution in a comparable manner. ${ }^{*} p<0.05$; ${ }^{* *} p<0.01$.

(data not shown). Therefore, it is unlikely that any subtle differences in neophobic response to a novel taste and/or preference for sweet solution could be responsible for the differential CS intake in the knock-out mice during the experiment.

To examine whether PAK3 knock-out mice learned to avoid a CS solution, we tested a subcohort of mice $(n=5$ for PAK3-; $n=6$ for PAK3 + ) $4.5 \mathrm{~h}$ after CS-US. This STM test revealed no differences in CS intake between knock-out and wild-type mice $\left(t_{(9)}=-0.4 ; p>0.05\right.$ ) (Fig. 7C), and mice of both genotypes initially learned equally well to avoid the grape solution. In contrast, the PAK3 knock-out mice showed a significantly impaired retention of learned taste aversion compared with their wild-type littermates $\left(F_{(1,19)}=6.6 ; p<0.02\right)$ (Fig. $\left.7 D\right)$. Because all CTA tests were performed in an extinction mode (mice did not experience nausea after ingesting CS solution during retests), it was likely that the observed increase in the intake of CS solution during retests was caused either by an accelerated extinction or by a deficit in memory retention in the knock-out mice. The analysis of performance during the STM test and the test performed on day 13 after CS-US did not reveal a significant genotype-by-day interaction that would indicate impairment in the memory retention. Although this result could be caused by a small number of tested mice, the present findings do not indicate unequivocally that PAK3 knock-out mice show an impairment in long-term memory. Last, the deletion of the Pak3 gene also did not affect the basic taste sensitivity of mice. The knock-out mice and their wildtype littermates showed comparable avoidance of bitter taste of $0.02 \%$ of quinine during a two-bottle (quinine vs water) test performed at the end of the experiment (Fig. 7E). 


\section{Discussion}

In this study, we created a novel mouse strain deficient in the expression of the nonsyndromic MRX gene Pak3. The biochemical, electrophysiological, and behavioral analyses indicate that PAK3 knock-out mice exhibit specific abnormalities in longlasting synaptic plasticity with markedly accelerated extinction of taste aversion memory. The knock-out mice also show reduced CREB function but normal actin cytoskeleton, suggesting that CREB-dependent gene expression may underlie the effects of PAK3 and potentially of other Rho proteins on synaptic regulation and behavioral responses. Our results provide strong evidence that abnormal CREB function may contribute to the cognitive deficits in MR patients.

Although PAKs are involved in the regulation of actin networks in many previous studies using cell lines (Bokoch, 2003; Zhao and Manser, 2005), the effect of the Pak3 deletion on neuronal actin cytoskeleton is minimal. One possibility is that PAK3 may normally play a role in actin regulation, but other members of the PAK family may have compensated for its functional loss. It is known that both PAK1 and PAK2 are expressed in the brain (Manser et al., 1994, 1995; Ong et al., 2002; Hayashi et al., 2004), but their total protein levels are not altered in PAK3 knock-out mice, suggesting that a functional compensation is unlikely. Creation and analysis of mutant mice lacking other members of PAKs and Rho kinases will be critical to evaluate functional compensation and redundancy. The absence of any actin deficits in the knock-out neuron is consistent with its apparently normal growth cones and spines, neuronal structures that are known to be enriched in actin filaments and require highly regulated actin dynamics. It is interesting to note, however, that transgenic mice expressing a dominant-negative form of PAK1 and knock-out mice lacking LIMK-1, a downstream effector protein kinase of PAKs, show significant abnormalities in spine morphology and neuronal actin cytoskeleton (Meng et al., 2002, 2003a; Hayashi et al., 2004). Although it remains to be investigated whether the PAK3 knock-out mice display any actin or spine deficits at specific developmental stages or in specific brain regions, our results suggest that members of PAKs may play distinct roles in neuronal functions with PAK3 important primarily in regulating activitydependent gene expression (see below).

In PAK3 knock-out mice, both basal synaptic strength and presynaptic function are normal. Furthermore, synaptic responses mediated by AMPA or NMDA receptors are not altered. These results, together with apparently normal synapses in PAK3 knock-out mice, suggest that PAK3 is not required for normal synaptic structures or proper synaptic targeting and functionality of glutamate receptors. In contrast, previous studies by manipulating PAK1 and PAK1-interacting proteins have shown that PAK1 contributes significantly to normal synaptic structures and glutamate receptor targeting, and this synaptic role is most likely mediated by regulating actin dynamics (Parnas et al., 2001; Albin and Davis, 2004; Hayashi et al., 2004). These results are consistent with the hypothesis that PAK1, but not PAK3, is involved in the regulation of the actin cytoskeleton and structural properties of the neuron.

Our study has provided several pieces of evidence that PAK3 may play a specific role in the regulation of neuronal gene expression related to synaptic plasticity. First, PAK3 knock-out mice exhibit a selective deficit in hippocampal L-LTP. Although the induction of both E-LTP and L-LTP depends on activation of NMDA receptors, their expression and maintenance require distinct signaling processes. Extensive studies indicate that the ex- pression of E-LTP involves transient posttranslational modifications, including protein phosphorylation and receptor trafficking at the synapse (Malenka and Nicoll, 1999; Bredt and Nicoll, 2003; Malinow and Malenka, 2002; Malenka and Bear, 2004), whereas L-LTP is maintained by activity-dependent gene expression, protein synthesis, and ultimately the formation of new synapses (Kandel, 2001; Silva, 2003; Kelleher et al., 2004; Lamprecht and LeDoux, 2004). Therefore, a deficit in L-LTP in PAK3 knock-out mice is consistent with a role for PAK3 in LTP-induced gene expression. Second, PAK3 knock-out mice show a significant reduction in the amount of phosphorylated or active CREB Ser133 , but no changes in the total CREB protein level, indicating that PAK3 is critically involved in regulating CREB activity and thus CREB-dependent gene transcription. The role of PAK3 in regulating gene expression is also consistent with the expression studies showing that PAK3 is predominantly expressed in the cell body and proximal dendrites, whereas PAK1 is concentrated in apical dendritic processes and dendritic spines of hippocampal neurons (Ong et al., 2002; Hayashi et al., 2004).

The exact mechanisms by which PAK3 regulates CREB Ser133 phosphorylation and/or dephosphorylation are unknown. Although PAKs can interact with several protein kinase cascades, including MAPK, PI 3-kinase/Akt, and PKA (Bokoch, 2003; Zhao and Manser, 2005), all of which are capable of regulating CREB Ser-133 phosphorylation (Impey et al., 1998; Lonze and Ginty, 2002; Silva, 2003; Thomas and Huganir, 2004), their activities do not appear to be affected in PAK3 knock-out mice. PAKs have also been shown to interact with and phosphorylate a number of protein phosphatases (Bokoch, 2003), but their roles in regulating CREB dephosphorylation remain to be determined. It is interesting to note that although basal pCREB is reduced in PAK3 knock-out slices, changes in pCREB induced by forskolin treatment remain intact, suggesting that stimulus-dependent CREB phosphorylation is not significantly impaired in these mice. However, it would be important to assess whether the effect of other stimuli, including synaptic activities, is altered in the knock-out mice.

Ample evidence indicates that CREB is not only important for synaptic plasticity but also for memory formation in mice (Kandel, 2001; Silva, 2003). Therefore, the reduced CREB function may also be responsible for the accelerated extinction of learned taste aversion in PAK3 knock-out mice. Although the neural mechanisms underlying the robust and long-lasting association of taste aversion and nausea have yet to be elucidated, several brain areas have been implicated, including the amygdala and cortex. It has been shown that protein synthesis and new gene expression in the central amygdala are required for CTA memory (Lamprecht and Dudai, 1996). Furthermore, several studies have indicated that the amygdala CREB is essential for long-term CTA memory or for the retrieval of already formed long-term memory (Lamprecht et al., 1997; Balschun et al., 2003; Josselyn et al., 2004). Our present behavioral findings closely replicate this type of dysfunction in CTA, thus also strongly implicating PAK3 involvement in regulating CREB activity in the brain. Future studies will attempt to characterize the level of CREB activity in the amygdala and cortex with reference to affected types of memories (e.g., extinction or long-term memory). It will also be important to test whether increasing CREB function can restore or ameliorate the synaptic and cognitive deficits in PAK3 knock-out mice. Functional rescues by manipulating CREB activity have already been demonstrated for other mouse models with deficits in L-LTP and long-term memory, including CREB-binding protein mutant mice (Barad et al., 1998; Bourtchuladze et al., 2003; Alar- 
con et al., 2004; Korzus et al., 2004). Finally, it is interesting to note that although hippocampal CREB function and L-LTP are impaired in PAK3 knock-out mice, their spatial learning and memory in the MWM test does not appear to be significantly perturbed. Because some mutant mice with altered hippocampal LTP may show deficits in some, but not in all, behavioral paradigms designed for assessing hippocampal-dependent spatial learning and memory (Alarcon et al., 2004; Korzus et al., 2004), additional tests with alternative paradigms or using mice with different genetic backgrounds are clearly needed. Nevertheless, our results are consistent with a number of previous studies demonstrating that mice with altered CREB function are not impaired in at least some forms of hippocampus-dependent reference memory but markedly perturbed in hippocampusindependent CTA performance (Graves et al., 2002; Balschun et al., 2003). Because CREB is involved in many other cellular processes (Lonze and Ginty, 2002), the PAK-CREB signaling pathway that we have identified in the mouse brain could also provide an important mechanism mediating the effects of the Rho GTPases on cell growth, cell survival, and apoptotic cell death.

In summary, the results presented in this study provided evidence that PAK3 knock-out mice are impaired in both synaptic plasticity and cognition. Therefore, these mice can be used as an important model for studying nonsyndromic MR. Additional analysis of PAK3 knock-out mice, including a detailed investigation of synaptic and behavioral properties in various genetic backgrounds, may provide important clues for elucidating the mechanisms of this mental disorder.

\section{References}

Alarcon JM, Malleret G, Touzani K, Vronskaya S, Ishii S, Kandel ER, Barco A (2004) Chromatin acetylation, memory, and LTP are impaired in $\mathrm{CBP}^{+/-}$mice: a model for the cognitive deficit in Rubinstein-Taybi Syndrome and its amelioration. Neuron 42:947-959.

Albin SD, Davis GW (2004) Coordinating structural and functional synapse development: postsynaptic p21-activated kinase independently specifies glutamate receptor abundance and postsynaptic morphology. J Neurosci 24:6871-6879.

Allen KM, Gleeson JG, Bagrodia S, Patington MW, MacMillan JC, Cerione RA, Mulley JC, Walsh CA (1998) PAK3 mutation in nonsyndromic X-linked mental retardation. Nat Genet 20:25-30.

Balschun D, Wolfer DP, Gass P, Mantamadiotis T, Welzl H, Schutz G, Frey JU, Lipp HP (2003) Does cAMP response element-binding protein have a pivotal role in hippocampal synaptic plasticity and hippocampusdependent memory? J Neurosci 23:6304-6314.

Barad M, Bourtchouladze R, Winder DG, Golan H, Kandel E (1998) Rolipram, a type IV-specific phosphodiesterase inhibitor, facilitates the establishment of long-lasting long-term potentiation and improves memory. Proc Natl Acad Sci USA 95:15020-15025.

Bear MF, Abraham WC (1996) Long-term depression in the hippocampus. Annu Rev Neurosci 19:437-462.

Bliss TVP, Collingridge GL (1993) A synaptic model of memory: long-term potentiation in the hippocampus. Nature 361:31-39.

Boda B, Mas C, Muller D (2002) Activity-dependent regulation of genes implicated in X-linked non-specific mental retardation. Neuroscience 114:13-17.

Boda B, Alberi S, Nikonenko I, Node-Langlois R, Jourdain P, Moosmayer M, Parisi-Jourdain L, Muller D (2004) The mental retardation protein PAK3 contributes to synapse formation and plasticity in hippocampus. J Neurosci 24:10816-10825.

Bokoch GM (2003) Biology of p21-activated kinases. Annu Rev Biochem 72:743-781.

Bonhoeffer T, Yuste R (2002) Spine motility. Phenomenology, mechanisms, and function. Neuron 35:1019-1027.

Bourtchuladze R, Lidge R, Catapano R, Stanley J, Gossweiler S, Romashko D, Scott R, Tully T (2003) A mouse model of Rubinstein-Taybi syndrome: defective long-term memory is ameliorated by inhibitors of phosphodiesterase 4. Proc Natl Acad Sci USA 100:10518-10522.
Bredt DS, Nicoll RA (2003) AMPA receptor trafficking at excitatory synapses. Neuron 40:361-379.

Chelly J, Mandel J (2001) Monogenic causes of X-linked mental retardation. Nat Rev Genet 2:669-680.

Chiurazzi P, Oostra BA (2000) Genetics of mental retardation. Curr Opin Pediatr 12:529-535.

Costa RM, Yang T, Huynh DP, Pulst SM, Viskochil DH, Silva AJ, Brannan CI (2001) Learning deficits, but normal development and tumor predisposition, in mice lacking exon 23a of Nf1. Nat Genet 27:399-405.

Dutch-Belgium Fragile X Consortium (1994) Fmr1 knockout mice: a model to study fragile X mental retardation. The Dutch-Belgian Fragile X Consortium. Cell 78:23-33.

Fukazawa Y, Saitoh Y, Ozawa F, Ohta Y, Mizuno K, Inokuchi K (2003) Hippocampal LTP is accompanied by enhanced F-actin content within the dendritic spine that is essential for late LTP maintenance in vivo. Neuron 38:447-460.

Gallagher M, Burwell R, Burchinal M (1993) Severity of spatial learning impairment in aging: development of learning index for performance in the Morris water maze. Behav Neurosci 107:618-626.

Govek EE, Newey SE, Akerman CJ, Cross JR, Van der Veken L, Van Aelst L (2004) The X-linked mental retardation protein oligophrenin-1 is required for dendritic spine morphogenesis. Nat Neurosci 7:364-372.

Graves L, Dalvi A, Lucki I, Blendy JA, Abel T (2002) Behavioral analysis of CREB alphadelta mutation on a B6/129 F1 hybrid background. Hippocampus 12:18-26.

Hall A (1998) Rho GTPases and the actin cytoskeleton. Science 279:509-514.

Hayashi ML, Choi SY, Rao BS, Jung HY, Lee HK, Zhang D, Chattarji S, Kirkwood A, Tonegawa S (2004) Altered cortical synaptic morphology and impaired memory consolidation in forebrain-specific dominantnegative PAK transgenic mice. Neuron 42:773-787.

Impey S, Obrietan K, Wong ST, Poser S, Yano S, Wayman G, Deloulme JC, Chan G, Storm DR (1998) Cross talk between ERK and PKA is required for $\mathrm{Ca}^{2+}$ stimulation of CREB-dependent transcription and ERK nuclear translocation. Neuron 21:869-883.

Ishikawa Y, Katoh H, Negishi M (2003) Role of Rnd1 GTPase in dendritic spine formation in hippocampal neurons. J Neurosci 23:11065-11072.

Janus C (2004) Search strategies used by APP transgenic mice during spatial navigation in the Morris water maze. Learn Mem 11:337-346.

Jia ZP, Agopyan N, Miu P, Xiong Z, Henderson J, Gerlai R, Taverna F, Velumian A, MacDonald JF, Carlen P, Abranow-Newerly W, Roder J (1996) Enhanced LTP in mice deficient in the AMPA receptor, GluR2. Neuron 17:945-956.

Josselyn SA, Kida S, Silva AJ (2004) Inducible repression of CREB function disrupts amygdala-dependent memory. Neurobiol Learn Mem 82:159-163.

Kandel ER (2001) The molecular biology of memory storage: a dialogue between genes and synapses. Science 294:1030-1038.

Kelleher III RJ, Govindarajan A, Tonegawa S (2004) Translational regulatory mechanisms in persistent forms of synaptic plasticity. Neuron 44:69-73.

Kohn M, Steinbach P, Hameister H, Kehrer-Sawatzki H (2004) A comparative expression analysis of four MRX genes regulating intracellular signalling via small GTPases. Eur J Hum Genet 12:29-37.

Korzus E, Rosenfeld MG, Mayford M (2004) CBP histone acetyltransferase activity is a critical component of memory consolidation. Neuron 42:961-972.

Lamprecht R, Dudai Y (1996) Transient expression of c-Fos in rat amygdala during training is required for encoding conditioned taste aversion memory. Learn Mem 3:31-41.

Lamprecht R, LeDoux J (2004) Strucural plasticity and memory. Nat Rev Neurosci 5:45-54.

Lamprecht R, Hazvi S, Dudai Y (1997) cAMP response element-binding protein in the amygdala is required for long- but not short-term conditioned taste aversion memory. J Neurosci 17:8443-8450.

Lisman J (2003) Actin's action in LTP-induced synapse growth. Neuron 38:361-365.

Lonze BE, Ginty DD (2002) Function and regulation of CREB family transcription factors in the nervous system. Neuron 35:605-623.

Luo L (2000) Rho GTPases in neuronal morphogenesis. Nat Rev Neurosci $1: 173-180$. 
Luo L (2002) Actin cytoskeleton regulation in neuronal morphogenesis and structural plasticity. Annu Rev Cell Dev Biol 18:601-635.

Meachum CL, Bernstein IL (1990) Conditioned responses to a taste conditioned stimulus paired with lithium chloride administration. Behav Neurosci 104:711-715.

Malenka RC, Bear MF (2004) LTP and LTD: an embarrassment of riches. Neuron 30:5-21.

Malenka RC, Nicoll RA (1999) Long-term potentiation-a decade of progress? Science 285:1870-1874.

Malinow R, Malenka RC (2002) AMPA receptor trafficking and synaptic plasticity. Annu Rev Neurosci 25:103-126.

Manser E, Leung T, Salihuddin H, Zhao ZS, Lim LA (1994) Brain serine/ threonine protein kinase activated by $\mathrm{Cdc} 42$ and Racl. Nature $367: 40-46$.

Manser E, Chong C, Zhao ZS, Leung T, Michael G, Hall C, Lim L (1995) Molecular cloning of a new member of the p21-Cdc42/Rac-activated kinase (PAK) family. J Biol Chem 270:25070-25078.

Matus A (2000) Actin-based plasticity in dendritic spines. Science 290:754-778.

Meng YH, Zhang Y, Tregoubov V, Janus C, Cruz L, Jackson M, Lu WY, MacDonald JF, Wang JY, Falls DL, Jia ZP (2002) Abnormal spine morphology and enhanced LTP in LIMK-1 knockout mice. Neuron 35:121-133.

Meng YH, Zhang Y, Tregoubov V, Falls DL, Jia ZP (2003a) Regulation of spine morphology and synaptic function by LIMK and the actin cytoskeleton. Rev Neurosci 14:233-240.

Meng YH, Zhang Y, Jia ZP (2003b) Synaptic transmission and plasticity in the absence of AMPA glutamate receptor GluR2 and GluR3. Neuron 39:163-176.

Nakayama AY, Harms MB, Luo L (2000) Small GTPases Rac and Rho in the maintenance of dendritic spines and branches in hippocampal pyramidal neurons. J Neurosci 20:5329-5338.

Okamoto K, Nagai T, Miyawaki A, Hayashi Y (2004) Rapid and persistent modulation of actin dynamics regulates postsynaptic reorganization underlying bidirectional plasticity. Nat Neurosci 7:1104-1112.

Ong WY, Wang XS, Manser E (2002) Differential distribution of alpha and beta isoforms of p21-activated kinase in the monkey cerebral neocortex and hippocampus. Exp Brain Res 144:189-199.

Parnas D, Haghighi AP, Fetter RD, Kim SW, Goodman CS (2001) Regula- tion of postsynaptic structure and protein localization by the Rho-type guanine nucleotide exchange factor dPix. Neuron 32:415-424.

Perkinton MS, Ip JK, Wood GL, Crossthwaite AJ, Williams RJ (2002) Phosphatidylinostol 3-kinase is a central mediator of NMDA receptor signaling to MAP kinase (Erk1/2), Akt/PKB and CREB in striatal neurons. J Neurochem 80:239-245.

Ramakers GJA (2002) Rho proteins, mental retardation and the cellular basis of cognition. Trends Neurosci 25:191-199.

Silva AJ (2003) Molecular and cellular cognitive of the role of synaptic plasticity in memory. J Neurobiol 54:224-237.

Silva AJ, Frankland PW, Marowitz Z, Friedman E, Laszlo GS, Cioffi D, Jacks T, Bourtchuladze R, Lazlo G (1997) A mouse model for the learning and memory deficits associated with neurofibromatosis type I. Nat Genet 15:281-284.

Smith RJ, Parker LA (1995) Chin rub CRs are elicited by flavors associated with apomorphine, scopolamine, methscopolamine, physostigmine and neostigmine. Pharmacol Biochem Behav 23:583-589.

Sorra KE, Harris KM (2000) Overview on the structure, composition, function, development, and plasticity of hippocampal dendritic spines. Hippocampus 10:501-511.

Stafstrom-Davis CA, Ouimet CC, Feng J, Allen PB, Greengard P, Houpt TA (2001) Impaired conditioned taste aversion learning in spinophilin knockout mice. Learn Mem 8:272-278.

Tashira A, Minden A, Yuste R (2000) Regulation of dendritic spine morphology by the Rho family small GTPases: antagonistic roles of Rac and Rho. Cereb Cortex 10:927-938.

Thomas GM, Huganir RL (2004) MAPK cascade signalling and synaptic plasticity. Nat Rev Neurosci 5:173-183.

Van Alest L, D'Souza-Schorey C (1997) Rho GTPases and signaling networks. Genes Dev 11:2295-2322.

Van Galen EJ, Ramakers GJ (2004) Rho proteins, mental retardation and the neurobiological basis of intelligence. Prog Brain Res 147:295-317.

Zhao ZS, Manser E (2005) PAK and other Rho-associated kinases-effectors with surprisingly diverse mechanisms of regulation. Biochem J 386:201-214.

Zito K, Knott G, Shepherd GM, Shenolikar S, Svoboda K (2004) Induction of spine growth and synapse formation by regulation of the spine actin cytoskeleton. Neuron 44:321-334. 